in vivo $34: 1111-1116(2020)$

doi:10.21873/invivo.11882

\title{
Association of Interleukin-4 Polymorphisms With Breast Cancer in Taiwan
}

\author{
CHIN-NAN CHU ${ }^{1,2}$, YUN-CHI WANG ${ }^{3}$, WEN-SHIN CHANG ${ }^{3}$, ZHI-HONG WANG ${ }^{4}$, LIANG-CHIH LIU ${ }^{3}$, \\ SHAO-CHUN WANG ${ }^{3}$, CHENG-CHIEH LIN ${ }^{3}$, TING-YUAN LIU ${ }^{3}$, JAN-GOWTH CHANG $^{3}$, \\ CHIA-WEN TSAI ${ }^{3 *}$, CHIEN-CHIH YU ${ }^{5 *}$ and DA-TIAN BAU ${ }^{1,3,6^{*}}$ \\ ${ }^{1}$ Graduate Institute of Clinical Medical Science, China Medical University, Taichung, Taiwan, R.O.C.; \\ ${ }^{2}$ Division of Radiation Oncology, China Medical University Hospital, Taichung, Taiwan, R.O.C.; \\ ${ }^{3}$ Terry Fox Cancer Research Laboratory, Department of Medical Research, \\ China Medical University Hospital, Taichung, Taiwan, R.O.C.; \\ ${ }^{4}$ Department of Food Nutrition and Health Biotechnology, Asia University, Taichung, Taiwan, R.O.C.; \\ ${ }^{5}$ School of Pharmacy, China Medical University, Taichung, Taiwan, R.O.C.; \\ ${ }^{6}$ Department of Bioinformatics and Medical Engineering, Asia University, Taichung, Taiwan, R.O.C.
}

\begin{abstract}
Background/Aim: The present study aimed at evaluating the contribution of IL-4 promoter T-1099G (rs2243248), C-589T (rs2243250), C-33T (rs2070874) genotypes to the risk of breast cancer in Taiwanese. Materials and Methods: A total of 1232 breast cancer patients and 1232 age-matched controls were genotyped by polymerase chain reaction-restriction fragment length polymorphism (PCRRFLP) methodology. Results: Genotypic frequencies of $I L-4$ rs2243248, rs2243250 and rs2070874 were not differentially distributed between case and control groups. Consistently, there was no difference in the distribution of allelic frequencies among patients and controls. Conclusion: IL-4 rs2243248, rs2243250 and rs2070874 do not confer breast cancer susceptibility in Taiwanese.
\end{abstract}

Breast cancer is the most invasive malignancy and has attracted high worldwide interest compared to other forms of death-causing cancers (1). Although the survival rates of breast cancer patients are increasing, breast cancer-related global deaths have been elevated to about $45 \%$ (1). In Taiwan, breast cancer has the highest incidence and is the

This article is freely accessible online.

*These Authors contributed equally to this study.

Correspondence to: Da-Tian Bau, Terry Fox Cancer Research Laboratory, Department of Medical Research, China Medical University Hospital, 2 Yuh-Der Road, Taichung, 404 Taiwan, R.O.C. Tel: +886 422053366 (Ext. 5805), e-mail: datian@mail.cmuh.org.tw; artbau2@gmail.com

Key Words: Breast cancer, genotype, $I L-4$, polymorphism, Taiwan. fourth leading cause of cancer-related mortality. The modern medical care system failed to reduce the mortality rate by nearly 2,000 persons per year during the past decade $(2,3)$. From the epidemiological viewpoint, the risk factors for breast cancer in Taiwanese women have been reported to be high-caloric intake, high-fat diets, early onset of menarche, relatively late of menopause, overweight or obesity, high levels of mental stress, and exposure to environmental pollutants (4).

In addition to these lifestyle and environmental factors, there are several hereditary factors waiting to be revealed. Histopathological markers, estrogen receptor (ER), progesterone receptor, and human epidermal growth factor receptor (HER2) are commonly used as diagnostic markers for further determination of clinical treatment, and almost 60 to $70 \%$ of breast cancer cases are ER/PR positive (5-8). Although these three markers are useful for treatment determination and drug response prediction, 10 to $20 \%$ of breast cancer patients are classified as triple negative, which is more aggressive form of breast cancer lacking a treatment target (9). That is, the three markers are not sufficient to cover all the heterogeneity of breast cancer (10). Since the breast cancer prevalence and mortality rates are extremely high in both Taiwan and the world, it is meaningful to identify novel genomic markers for early clinical detection and prognosis prediction.

Interleukin-4 (IL-4), which controls the maturation of $\mathrm{T}$ helper 2 cells $(11,12)$ and has been associated with asthma susceptibility (13), is mainly produced by macrophages and $\mathrm{T}$ lymphocytes $(11,12)$. IL-4 is a double-edged sword: it has been reported to mediate an antitumor effect (14-16), while, elevated IL-4 levels have been found in tumor tissues from patients with breast, renal cell, prostate, colon and lung cancer 
in vivo $34: 1111-1116(2020)$

Table I. Demographics and life style habits of the 1232 breast cancer patients and the 1232 healthy control Taiwanese women.

\begin{tabular}{|c|c|c|c|c|c|c|c|}
\hline \multirow[t]{2}{*}{ Characteristic } & \multicolumn{3}{|c|}{ Controls $(\mathrm{n}=1,232)$} & \multicolumn{3}{|c|}{ Patients $(\mathrm{n}=1,232)$} & \multirow[t]{2}{*}{$p$-Value } \\
\hline & $\mathrm{n}$ & $\%$ & Mean (SD) & $\mathrm{n}$ & $\%$ & Mean (SD) & \\
\hline \multicolumn{8}{|l|}{ Age (years) } \\
\hline$<40$ & 359 & $29.1 \%$ & & 362 & $29.4 \%$ & & $0.89^{\mathrm{a}}$ \\
\hline $40-55$ & 558 & $45.3 \%$ & & 547 & $44.4 \%$ & & \\
\hline$>55$ & 315 & $25.6 \%$ & & 323 & $26.2 \%$ & & \\
\hline Age at menarche (years) & & & $12.4(0.7)$ & & & $12.1(0.6)$ & $0.79^{\mathrm{b}}$ \\
\hline Age at birth of first child (years) & & & $29.4(1.2)$ & & & $29.8(1.4)$ & $0.63^{\mathrm{b}}$ \\
\hline Age at menopause (years) & & & $48.8(1.8)$ & & & $49.3(2.0)$ & $0.59^{\mathrm{b}}$ \\
\hline \multicolumn{8}{|l|}{ Tumor site } \\
\hline Unilateral & & & & 1198 & $97.2 \%$ & & \\
\hline Bilateral & & & & 34 & $2.8 \%$ & & \\
\hline \multicolumn{8}{|l|}{ Family history } \\
\hline $\begin{array}{l}\text { First degree (Mother, } \\
\text { sister, and daughter) }\end{array}$ & & & & 55 & $4.5 \%$ & & \\
\hline Second degree & & & & 6 & $0.5 \%$ & & \\
\hline No history & & & & 1171 & $95 \%$ & & \\
\hline \multicolumn{8}{|l|}{ Habit } \\
\hline Cigarette smoker & 86 & $7.0 \%$ & & 170 & $13.8 \%$ & & $<0.0001 * \mathrm{a}$ \\
\hline Alcohol drinker & 91 & $7.4 \%$ & & 162 & $13.1 \%$ & & $<0.0001^{* a}$ \\
\hline
\end{tabular}

${ }^{\mathrm{a} C h i}$-square or ${ }^{\mathrm{b}}$ unpaired Student's $t$-test; *Statistically significant.

(17). In addition, the growth of transplanted lung cancer cells has been shown to be delayed in IL-4 knock-out mice (18).

To date, the contribution of genotypic variations of $I L-4$ to cancer has not been well-studied. As for breast cancer, in 2009, the $I L-4$ VNTR polymorphism at its intron 3 was found not to be associated with risk for breast cancer among Indian women (19). In 2014, in a larger population consisting of 182 cases and 239 controls, the T allele at $I L$ $4 \mathrm{rs} 2243250$ was found to be associated with a reduced risk of breast cancer among Caucasians (20). In a meta-analysis study investigating a mixed population of 10,873 patients and 14,328 controls for IL4 rs2243250 genotypes, 3,970 patients and 5,686 controls for IL4 rs2070874 genotypes, and 1,896 patients and 2,526 controls for IL4 rs79071878 genotypes, a significant association with cancer risk was observed for rs2243250 and rs79071878 genotypes (21). In detail subgroup analysis by cancer type, rs2243250 genotypes were associated with risk for gastric and breast cancers; rs2070874 genotypes were associated with risk for leukemia and oral carcinoma, and rs79071878 genotypes were associated with risk for bladder carcinoma risk (21). In the subgroup analysis by ethnicity, IL4 rs2243250 genotypes were associated with risk for cancer in both Caucasian and Asian populations, rs2070874 genotypes were associated with cancer risk in Asian populations, while rs79071878 genotypes were associated with cancer risk in Caucasian populations (21). However, these $I L-4$ promoter SNPs have never been examined for their contribution to breast cancer among Taiwanese women. In the current study, we aimed to investigate the contribution of these most commonly investigated $I L-4$ promoter SNPs, the T-1099G (rs2243248), C-589T (rs2243250), and C-33T (rs2070874) genotypes, to the risk of breast cancer among Taiwanese women.

\section{Materials and Methods}

The study population of breast cancer cases and healthy control subjects. The current study was reviewed and approved by the Institutional Review Board of China Medical University Hospital (DMR99-IRB-108). Briefly, a total of 2464 subjects were recruited, including 1,232 female patients diagnosed with breast cancer and exactly the same number of age-matched healthy individuals visiting the China Medical University Hospital, one of the national medical centers in central Taiwan (22-24). The exclusion criteria for recruiting the healthy controls included any metastatic cancer of any origin, any previous malignancy, and any hereditary or genetic disease. Each participant had been carefully oriented to complete a selfadministered questionnaire before donating 3 to $5 \mathrm{ml}$ of peripheral blood. The questionnaire included questions on the personal medical history and several habits such as alcohol consumption and cigarette smoking. These factors were recorded and are concisely summarized in Table I. The informed consents of all enrolled persons were collected and kept in the tissue-bank at our hospital.

Methodology for IL-4 promoter polymorphic genotyping. Genomic DNA was extracted from peripheral blood leucocytes using the QIAamp Blood Mini Kit (Blossom, Taipei, Taiwan, ROC) and further processed by polymerase chain reaction-based restriction fragment length polymorphism methodology according to our previous 
Table II. Distributions of interleukin-4 (IL-4) genotypic frequencies among 1232 breast cancer cases and 1232 healthy controls in Taiwan.

\begin{tabular}{lcccc}
\hline & Cases (\%) & Controls (\%) & $\begin{array}{c}\text { Adjusted OR } \\
(95 \% \text { CI })^{\mathrm{a}}\end{array}$ & $p$-Value $^{\mathrm{b}}$ \\
\hline rs2243248 & & & & \\
TT & $1024(83.1)$ & $1051(85.3)$ & 1.00 (reference) & \\
TG & $195(15.8)$ & $170(13.8)$ & $1.12(0.92-1.37)$ & 0.1510 \\
GG & $13(1.1)$ & $11(0.9)$ & $1.14(0.61-2.42)$ & 0.6388 \\
$p$ for & & & & 0.3279 \\
trend & & & & \\
rs2243250 & & & & \\
TT & $818(66.4)$ & $850(69.0)$ & $1.00($ reference) & \\
CT & $366(29.7)$ & $345(28.0)$ & $1.07(0.89-1.26)$ & 0.2767 \\
CC & $48(3.9)$ & $37(3.0)$ & $1.18(0.86-2.17)$ & 0.1814 \\
$p$ for & & & & 0.2648 \\
trend & & & & \\
rs2070874 & & & & \\
TT & $799(64.9)$ & $815(66.2)$ & $1.00($ reference) & \\
CT & $391(31.7)$ & $382(31.0)$ & $1.06(0.85-1.31)$ & 0.6221 \\
CC & $42(3.4)$ & $35(2.8)$ & $1.15(0.73-1.86)$ & 0.3874 \\
$p$ for & & & & 0.6377 \\
trend & & & & \\
\hline
\end{tabular}

OR: Odds ratio; CI: confidence interval. aData has been adjusted with confounding factors include age, smoking and alcohol drinking status. bBased on Chi-square test without Yates' correction test; ${ }^{*} p<0.05$.

publications (25-27). The routine PCR cycling conditions were set as: one cycle at $94^{\circ} \mathrm{C}$ for $5 \mathrm{~min} ; 35$ cycles of $94^{\circ} \mathrm{C}$ for $30 \mathrm{sec}, 55^{\circ} \mathrm{C}$ for 30 sec, and $72^{\circ} \mathrm{C}$ for $30 \mathrm{sec}$; and a final extension at $72^{\circ} \mathrm{C}$ for $10 \mathrm{~min}$. The sequences of the primers for $I L-4$ rs 2243248 were: forward 5'GGTCCTTACGTTCACTGCTG-3' and reverse 5'- GGCTCAAGTG CTCCTCCTAC- 3 '. The sequences of the primers for $I L-42243250$ were: forward 5'-TAAACTTGGGAGAACATGGT-3' and reverse 5'TGGGGAAAGATAGAGTAATA-3'. The sequences of the primers for IL-4 rs2070874 were: forward 5'-CTGGAAGAGAGGTGCTGATT-3' and reverse 5'-ACTCACCTTCTGCTCTGTGA-3'. The PCR products for IL-4 rs2243248, rs2243250 and rs2070874 genotyping were digested with $S f c \mathrm{I}, A v a \mathrm{II}$ and BsmAI, respectively. The products of the digestions were analyzed in a 3\% agarose gel electrophoresis under 100 volt for $30 \mathrm{~min}$ and photographed for identification of the genotype. All the genotypic processing was performed independently and blindly by two researchers, whose results were $100 \%$ concordant to each other. The success rate of the PCR-RFLP procedure was $100 \%$.

Statistical methodology for IL-4 promoter polymorphic genotyping. To ensure that the control subjects were representative of the Taiwanese population and to exclude genotyping errors, the fitness of the genotypic frequencies of $I L-4$ genotypes for the examined polymorphic sites in the healthy control group was evaluated with the Hardy-Weinberg equilibrium via the goodness-of-fit analysis. In addition, the Pearson's chi-square statistical methodology was adopted to examine the distributions of $I L-4$ polymorphic genotypes between the subgroups. The associations between each $I L-4$ genotype and cancer risk were estimated via the calculated outcomes of odds ratios (ORs) together with the corresponding 95\% confidence intervals (CIs) via unconditional logistic regression before and after the adjustments for age, smoking and alcohol drinking habits.
Table III. Allele frequencies of interleukin-4 (IL-4) among 1232 breast cancer cases and 1232 healthy controls in Taiwan.

\begin{tabular}{rcccc}
\hline Allele & $\begin{array}{c}\text { Cases (\%) } \\
\mathrm{n}=2464\end{array}$ & $\begin{array}{c}\text { Controls (\%) } \\
\mathrm{n}=2464\end{array}$ & $\begin{array}{c}\text { Adjusted OR } \\
(95 \% \mathrm{CI})^{\mathrm{a}}\end{array}$ & $p$-Value \\
\hline rs2243248 & & & & \\
Allele T & $2243(91.0)$ & $2272(92.2)$ & 1.00 (reference) & 0.1360 \\
Allele G & $221(9.0)$ & $192(7.8)$ & $1.13(0.92-1.37)$ & \\
rs2243250 & & & & \\
Allele T & $2002(81.3)$ & $2045(83.0)$ & 1.00 (reference) & 0.1099 \\
Allele C & $462(18.7)$ & $419(17.0)$ & $1.09(0.94-1.28)$ & \\
rs2070874 & & & & \\
Allele T & $1989(80.7)$ & $2012(81.7)$ & 1.00 (reference) & 0.4018 \\
Allele C & $475(19.3)$ & $452(18.3)$ & $1.08(0.89-1.24)$ & \\
\hline
\end{tabular}

OR: Odds ratio; CI: confidence interval. aData has been adjusted with confounding factors include age, smoking and alcohol drinking status. bBased on Chi-square test without Yates' correction test. ${ }^{*} p<0.05$.

\section{Results}

The distributions of frequencies of the demographic characteristics for the breast cancer patients and healthy controls are shown in Table I. There was no statistical difference between the case and control groups regarding age, age at menarche, age at birth of first child, or age at menopause $(p>0.05)$. Regarding personal habits, it was shown that higher percentages of breast cancer patients (13.8 and $13.1 \%)$ than the healthy controls $(7.0$ and $7.4 \%)$ are cigarette smokers and alcohol drinkers (both $p<0.0001$ ) (Table I).

The $I L-4$ T-1099G (rs2243248), C-589T (rs2243250), and C-33T (rs2070874) genotypic distributions among the breast cancer cases and controls are shown in Table II. First, there was no association between the genotype of rs 2243248 , rs2243250 or rs 2070874 and breast cancer susceptibility in Taiwanese women (all $p$ for trend and $p$-values are larger than 0.05) (Table II). Even after adjusting the confounding factors including age, smoking and alcohol drinking habits, the heterozygous and homozygous genotypes at rs2243248, rs2243250 or rs2070874 still do not associate with increased breast cancer risk (Table II).

To confirm these findings based on the genotypic frequency distribution in Table II, the allelic frequency distribution for the three $I L-4$ promoter SNPs was also conducted and the results are shown in Table III. In support, none of the genotypes at $I L$ 4 rs2243248, rs2243250 and rs2070874 was associated with breast cancer risk, none of the variant alleles at IL-4 rs2243248, rs2243250 or rs 2070874 was significantly associated with breast cancer risk (all $p$-values were larger than 0.05).

Overall, all the findings presented in Tables II and III support the temporary conclusion that none of the $I L-4$ rs2243248, rs2243250 or rs2070874 genotypes can serve as a predictor for breast cancer. 


\section{Discussion}

Chronic inflammation observed during carcinogenesis is exerted and regulated by a complicated network of chemokines, sex hormones (such as prostaglandins and estrogens), and cytokines (28). Among the cytokines, IL-4 has been associated with the etiology for various types of cancer. It has been shown that elevated levels of IL-4 in the plasma were closely associated with the risk for melanoma, head and neck squamous carcinoma, prostate, colon, renal cell, small cell lung cancer, acute myeloid leukemia and most of all, breast cancer (29-31). However, there is also a study reporting that serum levels of IL-4 in breast cancer are decreased (32). These conflicting evidence shows that IL-4 may be a double-edged sword in breast cancer and may be arbitrary to predict breast cancer risk from simply the expression levels of serum IL-4. Several IL-4 SNPs have been associated with the risk for several types of cancer, such as bladder cancer (33), gastric cancer (34), glioblastoma (35), and pancreatic cancer (36). In the current study, the contribution of three SNPs at the promoter region of $I L-4$ (T1099G, C-589T and C-33T) to breast cancer risk was evaluated in a large and representative Taiwanese population consisting of 1232 breast cancer patients and 1232 healthy controls. The results showed no obvious differential distribution of the genotypes of $I L-4$ promoter T-1099G (rs2243248), C-589T (rs2243250) or C-33T (rs2070874) (Tables II and III). According to previous studies, the CT and CC genotypes at $I L-4$ rs2243250 are associated with a decreased expression of IL-4 $(37,38)$, and the allele C at $I L$ $4 \mathrm{rs} 2243250$ is also associated with a lower expression of $I L$ $4(39,40)$. All the above evidence showed that the $\mathrm{C}$ allele at $I L-4$ rs2243250 may be responsible for the regulation of IL-10 mRNA and protein expression. Although we did not find a positive association of rs 2243250 or of the other two polymorphisms with breast cancer risk, we could not exclude the possibility that other SNPs in $I L-4$ may contribute to the etiology and progression of breast cancer.

Breast cancer is not a gender-specific cancer since few men are afflicted by this disease, but it is a smoking-related cancer. In the current study, all the participants were women. Furthermore, our results showed that the genotypic distribution of the variant genotypes of $I L-4$ rs2243248, rs2243250 or rs2070874 were not significantly different between breast cancer and control groups who were eversmokers or non-smokers (data not shown). In 2007, CesarNeto and his colleagues reported that smoking behavior decreased the levels of TNF- $\alpha$, MMP- 8 , IL- $1 \alpha$, IL-8, IL-10 and osteoprotegerin in periodontitis tissues, but not that of IL-4 (41). To date, there is no solid evidence from any cell or animal model indicating that a change in the levels of IL4 expression plays a critical role in breast cancer initiation or progression. We also found that there was no interaction between the $I L-4$ genotype and alcohol drinking status among the participants (data not shown). In conclusion, the three $I L-4$ promoter polymorphic sites were not found to contribute to breast cancer risk determination.

\section{Conflicts of Interest}

The Authors declare no conflict of interest in regard to this study.

\section{Authors' Contributions}

Research design: Chu CN, Tsai CW, Yu CC; patient and questionnaire summaries: Liu LC, Lin CC; experimental work: Wang YC, Chang WS, Wang ZH; statistical analysis: Wang SC, Liu TY, Chang JG; manuscript writing: Tsai CW, Bau DT; review \& revision: Tsai CW, Yu CC, Bau DT.

\section{Acknowledgements}

The Authors appreciate Tissue-bank of China Medical University Hospital for their long-term technical assistance and all the participants, doctors, nurses and colleagues. The technical help from Yu-Ting Chin, Tai-Lin Huang, Yu-Hsin Lin and Yi-Ru Huang is respected by all the Authors. This study was supported mainly by China Medical University Hospital to Dr. Chu (DMR-109-054).

\section{References}

1 Siegel RL, Miller KD and Jemal A: Cancer statistics, 2017. CA Cancer J Clin 67: 7-30, 2017. PMID: 28055103. DOI: 10.3322/caac. 21387

2 Chien LH, Tseng TJ, Chen CH, Jiang HF, Tsai FY, Liu TW, Hsiung CA and Chang IS: Comparison of annual percentage change in breast cancer incidence rate between Taiwan and the United States-A smoothed Lexis diagram approach. Cancer Med 6: 1762-1775, 2017. PMID: 28560749. DOI: 10.1002/cam4.1102

32 Taiwan Ministry of Health and Welfare Clinical Trial and Research Center of Excellence: Cancer Registration Annual Report. Available from: https:/www.hpa.gov.tw/Pages/ List.aspx ? nodeid $=269$ (Last accessed on January 31 ${ }^{\text {th }}, 2020$ )

4 Tsai HY, Kuo RN and Chung KP: Quality of life of breast cancer survivors following breast-conserving therapy versus mastectomy: a multicenter study in Taiwan. Jpn J Clin Oncol 47: 909-918, 2017. PMID: 28981734. DOI: 10.1093/jjco/hyx099

5 Hamam R, Hamam D, Alsaleh KA, Kassem M, Zaher W, Alfayez M, Aldahmash A and Alajez NM: Circulating microRNAs in breast cancer: novel diagnostic and prognostic biomarkers. Cell Death Dis 8: e3045, 2017. PMID: 28880270. DOI: $10.1038 /$ cddis.2017.440

6 Hashemi S, Sadeghi M, Vahedi Tabas A, Bouya S, Danesh HA, Khazaei A and Allahyari A: Serum levels of selenium and zinc in patients with breast cancer: A case-control study. Int J Cancer Manag 10: e11463, 2017. DOI: 10.5812/ijcm.11463

7 Tabarestani S, Motallebi M, Akbari ME, Malekzadeh Moghani $\mathrm{M}$ and Shojaee L: Analysis of BRCA1/2 mutations and performance of manchester scoring system in high risk Iranian breast cancer patients: A pilot study. Int J Cancer Manag 10: e60392, 2017. DOI: 10.5812/ijcm.60392 
8 Zahmatkesh BH, Alavi N, Keramat A, Khosravi A and Chaman R: Body mass index and risk of breast cancer: A systematic review and metaanalysis in Iran. Int J Cancer Manag 10: e5921, 2017. DOI: $10.5812 / \mathrm{ijcm} .5921$

9 Carey LA, Perou CM, Livasy CA, Dressler LG, Cowan D, Conway K, Karaca G, Troester MA, Tse CK, Edmiston S, Deming SL, Geradts J, Cheang MC, Nielsen TO, Moorman PG, Earp HS and Millikan RC: Race, breast cancer subtypes, and survival in the Carolina Breast Cancer Study. JAMA 295: 2492-2502, 2006. PMID: 16757721. DOI: 10.1001/jama. 295.21.2492

10 Dowsett $\mathrm{M}$ and Dunbier AK: Emerging biomarkers and new understanding of traditional markers in personalized therapy for breast cancer. Clin Cancer Res 14: 8019-8026, 2008. PMID: 19088018. DOI: 10.1158/1078-0432.CCR-08-0974

11 Paul WE: Interleukin-4: a prototypic immunoregulatory lymphokine. Blood 77: 1859-1870, 1991. PMID: 2018830.

12 Amsen D, Spilianakis CG and Flavell RA: How are $\mathrm{T}(\mathrm{H}) 1$ and $\mathrm{T}(\mathrm{H}) 2$ effector cells made? Curr Opin Immunol 21: 153-160, 2009. PMID: 19375293. DOI: 10.1016/j.coi.2009.03.010

13 Steinke JW and Borish L: Th2 cytokines and asthma. Interleukin4: its role in the pathogenesis of asthma, and targeting it for asthma treatment with interleukin-4 receptor antagonists. Respir Res 2: 66-70, 2001. PMID: 11686867. DOI: 10.1186/rr40

14 Pardoll DM: Paracrine cytokine adjuvants in cancer immunotherapy. Annu Rev Immunol 13: 399-415, 1995. PMID: 7612229. DOI: 10.1146/annurev.iy.13.040195.002151

15 Rodolfo M, Zilocchi C, Accornero P, Cappetti B, Arioli I and Colombo MP: IL-4-transduced tumor cell vaccine induces immunoregulatory type $2 \mathrm{CD} 8 \mathrm{~T}$ lymphocytes that cure lung metastases upon adoptive transfer. J Immunol 163: 1923-1928, 1999. PMID: 10438927.

16 Tepper RI, Pattengale PK and Leder P: Murine interleukin-4 displays potent anti-tumor activity in vivo. Cell 57: 503-512, 1989. PMID: 2785856. DOI: 10.1016/0092-8674(89)90925-2

17 Shurin MR, Lu L, Kalinski P, Stewart-Akers AM and Lotze MT: Th1/Th2 balance in cancer, transplantation and pregnancy. Springer Semin Immunopathol 21: 339-359, 1999. PMID: 10666777. DOI: $10.1007 / \mathrm{bf00812261}$

18 Kemp RA and Ronchese F: Tumor-specific Tc1, but not Tc2, cells deliver protective antitumor immunity. J Immunol 167: 6497-6502, 2001. PMID: 11714817. DOI: 10.4049/jimmunol. 167.11 .6497

19 Konwar R, Chaudhary P, Kumar S, Mishra D, Chattopadhyay N and Bid HK: Breast cancer risk associated with polymorphisms of IL-1RN and IL-4 gene in Indian women. Oncol Res 17: 367372, 2009. PMID: 19544973. DOI: $10.3727 / 09650400978842$ 8442

20 Joshi NN, Bhat S, Hake S, Kale M and Kannan S: Opposing effects of pro- and anti-inflammatory cytokine gene polymorphisms on the risk for breast cancer in western Indian women: a pilot study. Int J Immunogenet 41: 242-249, 2014. PMID: 24164868. DOI: 10.1111/iji.12098

$21 \mathrm{Jia}$ Y, Xie X, Shi X and Li S: Associations of common IL-4 gene polymorphisms with cancer risk: A meta-analysis. Mol Med Rep 16: 1927-1945, 2017. PMID: 28656227. DOI: 10.3892/mmr. 2017.6822

22 Tsai CW, Chang WS, Shen TC, Su CH, Wang HC, Liu LC and Bau DT: Contribution of excision repair cross-complementing group 1 genotypes to triple negative breast cancer risk. PLoS
One 13: e0202112, 2018. PMID: 30096175. DOI: 10.1371/ journal.pone.0202112

23 Hsiao CL, Liu LC, Shih TC, Lai YL, Hsu SW, Wang HC, Pan SY, Shen TC, Tsai CW, Chang WS, Su CH, Way TD, Chung JG and Bau DT: The association of matrix metalloproteinase-1 promoter polymorphisms with breast cancer. In Vivo 32: 487491, 2018. PMID: 29695550. DOI: 10.21873/invivo.11265

24 Hsiao CL, Liu LC, Shih TC, Chuang CL, Chen GL, Wang HC, Pan SY, Shen TC, Tsai CW, Chang WS, Way TD, Chung JG and Bau DT: The association of matrix metalloproteinase- 8 promoter genotypes in breast cancer. Anticancer Res 38: 2181-2185, 2018. PMID: 29599337. DOI: 10.21873/anticanres.12459

25 Chang WS, Wang SC, Chuang CL, Ji HX, Hsiao CL, Hsu CM, Tsai CW, Liu SP, Hsu PC, Lo YL and Bau DT: Contribution of interleukin-4 genotypes to lung cancer risk in Taiwan. Anticancer Res 35: 6297-6301, 2015. PMID: 26504066.

$26 \mathrm{Hu}$ PS, Wang YC, Liao CH, Hsia NY, Wu MF, Yang JS, Yu CC, Chang WS, Bau DT and Tsai CW: The association of MMP7 genotype with pterygium. In Vivo 34: 51-56, 2020. PMID: 31882462. DOI: 10.21873 /invivo. 11744

27 Hsu SW, Gong CL, Hsu HM, Chao CC, Wang YC, Chang WS, Tsai YT, Shih LC, Tsai CW and Bau DT: Contribution of matrix metalloproteinase-2 promoter genotypes to nasopharyngeal cancer susceptibility and metastasis in Taiwan. Cancer Genomics Proteomics 16: 287-292, 2019. PMID: 31243109. DOI:10. 21873/cgp.20133

28 Harvey RD and Morgan ET: Cancer, inflammation, and therapy: effects on cytochrome p450-mediated drug metabolism and implications for novel immunotherapeutic agents. Clin Pharmacol Ther 96: 449-457, 2014. PMID: 24987833. DOI: $10.1038 / \mathrm{clpt} .2014 .143$

29 Sanchez-Correa B, Bergua JM, Campos C, Gayoso I, Arcos MJ, Banas H, Morgado S, Casado JG, Solana R and Tarazona R: Cytokine profiles in acute myeloid leukemia patients at diagnosis: survival is inversely correlated with IL-6 and directly correlated with IL-10 levels. Cytokine 61: 885-891, 2013. PMID: 23357299. DOI: 10.1016/j.cyto.2012.12.023

30 Porter GA, Abdalla J, Lu M, Smith S, Montgomery D, Grimm E, Ross MI, Mansfield PF, Gershenwald JE and Lee JE: Significance of plasma cytokine levels in melanoma patients with histologically negative sentinel lymph nodes. Ann Surg Oncol 8: 116-122, 2001. PMID: 11258775. DOI: 10.1007/ s10434-001-0116-3

31 Lathers DM and Young MR: Increased aberrance of cytokine expression in plasma of patients with more advanced squamous cell carcinoma of the head and neck. Cytokine 25: 220-228, 2004. PMID: 15036248. DOI: 10.1016/j.cyto.2003.11.005

32 Al-Ghurabi BH. IL-2 and IL-4 serum levels in breast cancer. J Fac Med Baghdad 51: 300-303, 2009.

33 Bozdogan ST, Erol B, Dursun A, Bozdogan G, Donmez I, Mungan NA and Seydaoglu G: The IL-1RN and IL-4 gene polymorphisms are potential genetic markers of susceptibility to bladder cancer: a case-control study. World J Urol 33: 389395, 2015. PMID: 24850227. DOI: 10.1007/s00345-0141323-4

34 Pan XF, Wen Y, Loh M, Wen YY, Yang SJ, Zhao ZM, Tian Z, Huang H, Lan H, Chen F, Soong R and Yang CX: Interleukin-4 and -8 gene polymorphisms and risk of gastric cancer in a population in Southwestern China. Asian Pac J Cancer Prev 15: 2951-2957, 2014. PMID: 24815430. DOI: 10.7314/apjcp.2014.15.7.2951 
35 Jin T, Li X, Zhang J, Wang H, Geng T, Li G, Gao G and Chen $\mathrm{C}$ : Genetic association between selected cytokine genes and glioblastoma in the Han Chinese population. BMC Cancer 13: 236, 2013. PMID: 23663500. DOI: 10.1186/1471-2407-13-236

36 Olson SH, Orlow I, Simon J, Tommasi D, Roy P, Bayuga S, Ludwig E, Zauber AG and Kurtz RC: Allergies, variants in IL4 and IL-4R alpha genes, and risk of pancreatic cancer. Cancer Detect Prev 31: 345-351, 2007. PMID: 18031948. DOI: 10.1016/j.cdp.2007.10.002

37 Rosenwasser LJ, Klemm DJ, Dresback JK, Inamura H, Mascali $\mathrm{JJ}$, Klinnert $\mathrm{M}$ and Borish L: Promoter polymorphisms in the chromosome 5 gene cluster in asthma and atopy. Clin Exp Allergy 25(Suppl 2): 74-78; discussion 95-76, 1995. PMID: 8590350. DOI: 10.1111/j.1365-2222.1995.tb00428.x

38 Nakashima H, Miyake K, Inoue Y, Shimizu S, Akahoshi M, Tanaka Y, Otsuka T and Harada M: Association between IL-4 genotype and IL-4 production in the Japanese population. Genes Immun 3: 107-109, 2002. PMID: 11960309. DOI: 10.1038/ sj.gene. 6363830
39 Scarel-Caminaga RM, Trevilatto PC, Souza AP, Brito RB and Line SR: Frequencies of the -330 (T-->G) IL-2 and -590 (T-->C) IL-4 gene polymorphisms in a population from south-eastern Brazil. Eur J Immunogenet 29: 293-296, 2002. PMID: 12121273. DOI: 10.1046/j.1365-2370.2002.00314.x

40 Pawlik A, Wrzesniewska J, Florczak M, Gawronska-Szklarz B and Herczynska M: The -590 IL-4 promoter polymorphism in patients with rheumatoid arthritis. Rheumatol Int 26: 48-51, 2005. PMID: 15660235. DOI: 10.1007/s00296-004-0539-9

41 Cesar-Neto JB, Duarte PM, de Oliveira MC, Tambeli CH, Sallum EA and Nociti FH Jr.: Smoking modulates interleukin6:interleukin-10 and RANKL:osteoprotegerin ratios in the periodontal tissues. J Periodontal Res 42: 184-191, 2007. PMID: 17305878. DOI: 10.1111/j.1600-0765.2006.00934.x

Received January 31, 2020

Revised February 25, 2020

Accepted February 26, 2020 